\title{
Avaliação do ângulo nasolabial após o tratamento ortodôntico com e sem extração dos primeiros pré-molares
}

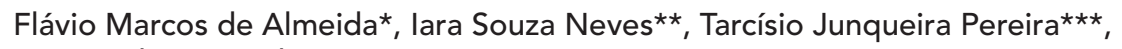
Vânia Célia Vieira de Siqueira****

\section{Resumo}

Objetivos: avaliar cefalometricamente as mudanças do ângulo nasolabial em pacientes submetidos ao tratamento ortodôntico com e sem exodontias dos primeiros pré-molares, e correlacionar este ângulo com as alterações na inclinação do incisivo superior, do lábio superior e da base do nariz. Metodologia: a amostra consistiu de telerradiografias iniciais e finais de 30 jovens do gênero feminino, com má oclusão de Classe II, $1^{\circ}$ divisão. Quinze foram tratadas com extração dos primeiros pré-molares e quinze sem extrações. Além do ângulo nasolabial, foram avaliadas as inclinações do lábio superior (Ls.PCm.SN7 ${ }^{\circ}$ ), do incisivo superior (Is.SN7 ${ }^{\circ}$ ) e da base do nariz ( $\left.\mathrm{PCm} . \mathrm{SN} 7^{\circ}\right)$. Resultados: a posição do lábio superior e a inclinação do incisivo superior foram as únicas medidas que apresentaram um aumento estatisticamente significante, entre os tempos inicial e final, no grupo com extrações. Todas as outras medidas avaliadas, em ambos os grupos, não apresentaram significância estatística. Observou-se uma correlação positiva entre a posição do lábio superior, a base do nariz e o ângulo nasolabial. Conclusões: 1) ocorreu um aumento significativo no ângulo nasolabial no grupo com exodontia dos primeiros pré-molares, devido, principalmente, às mudanças do lábio superior; 2) o crescimento nasal durante o período do estudo não influenciou nas alterações do ângulo nasolabial; 3) todas as outras medidas analisadas não apresentaram diferenças estatísticas entre os dois grupos, entre os tempos inicial e final; 4) observou-se uma correlação positiva entre o ângulo nasolabial, a inclinação do lábio superior e a base do nariz, em ambos os grupos.

Palavras-chave: Classe II, $1^{\text {a }}$ divisão. Ângulo nasolabial. Extração dentária. Perfil facial.

* Especialista e mestre em Ortodontia pela Pontifícia Universidade Católica de Minas Gerais - PUC/Minas. Professor assistente III da disciplina de Ortodontia da Pontifícia Universidade Católica de Minas Gerais - PUC/Minas.

** Cirurgiã-dentista formada pela Faculdade de Odontologia da Pontifícia Universidade Católica de Minas Gerais - PUC/Minas.

*** Especialista e mestre em Ortodontia pela Pontifícia Universidade Católica de Minas Gerais - PUC/Minas. Professor assistente III da disciplina de Ortodontia da Pontifícia Universidade Católica de Minas Gerais - PUC/Minas.

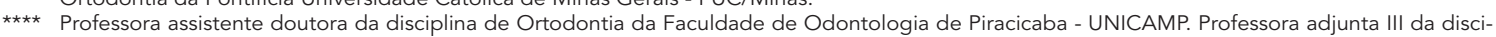
plina de Ortodontia da Pontifícia Universidade Católica de Minas Gerais - PUC/Minas. 


\section{INTRODUÇÃO}

A estética é, atualmente, a principal razão da procura do tratamento ortodôntico, e os ortodontistas buscam identificar os vários fatores que comprometem a harmonia facial. Ao saber o que pode alterar o perfil do paciente, é possivel prevenir mudanças indesejáveis em decorrência do tratamento ortodôntico.

O ângulo nasolabial é o ângulo formado pela borda inferior do nariz e filtro labial, com valores normais variando de 97 a 110 graus $^{1,11}$. Este ângulo é um componente significante na harmonia da face e parece relacionar-se com o tratamento ortodôntico. Alguns autores relataram que a retração dos incisivos superiores influencia no aumento do ângulo nasolabial, conseqüentemente modificando o perfil facial dos pacientes ${ }^{4,8,15}$. Outros fatores também parecem se associar com este ângulo, como a espessura do lábio superior e o tamanho e a inclinação do nariz ${ }^{8,15}$. A extração dentária, quando indicada no tratamento ortodôntico, mostra-se como um fator que pode estar relacionado indiretamente com a mudança do ângulo nasolabial, pois favorece a retração dos incisivos superiores ${ }^{2,4,8}$.

Durante o tratamento ortodôntico da Classe II, $1^{\text {a }}$ divisão, o crescimento parece não influenciar significativamente as alterações do ângulo nasolabial, diferentemente da retração dos incisivos superiores, que tem uma importância relevante neste aspecto ${ }^{7}$. O aumento do ângulo deve-se não só à retração dos incisivos superiores, mas também à sua verticalização ${ }^{15}$. Outros autores ${ }^{10}$, porém, afirmam que a individualidade do crescimento da base do nariz, e não necessariamente a anatomia do lábio superior, é a causa mais provável da variação no ângulo nasolabial.

A proporção entre a retração dos incisivos superiores e a alteração do ângulo nasolabial varia muito, mas sempre com valores significantes. Enquanto alguns autores ${ }^{14}$ observaram alterações de até $10,5^{\circ}$ no ângulo nasolabial para retrações acima de $3 \mathrm{~mm}$, outros ${ }^{2}$ encontraram um aumento de $5,2^{\circ}$ para uma retração média de $3,4 \mathrm{~mm}$. Um es- tudo longitudinal realizado em 36 pacientes com Classe II, $1^{\text {a }}$ divisão, demonstrou que, para cada milímetro de retração dos dentes ântero-superiores, o ângulo nasolabial aumenta 1,49 grau ${ }^{4}$. Independente da quantidade de retração e do aumento do ângulo nasolabial, muitos autores afirmaram que ocorre uma melhora na estética facial 2,4,14,15.

Outra proporção importante ocorre entre a quantidade de retração dos incisivos superiores e a quantidade de retração do lábio superior. Observase que a retração do lábio superior acompanha a retração dos incisivos superiores, em uma proporção média de $1 \mathrm{~mm}: 0,75 \mathrm{~mm}$ para pacientes com selamento labial antes do tratamento ortodôntico e de $1 \mathrm{~mm}: 0,70 \mathrm{~mm}$ para pacientes sem selamento. O movimento horizontal da cervical do incisivo superior é o que mais influencia nas mudanças do lábio superior. Existe uma variabilidade individual grande e um ângulo nasolabial obtuso não é resultado direto da retração do incisivo superior ${ }^{10}$.

Outros ângulos utilizados para avaliar o perfil facial tegumentar também se alteram com o tratamento ortodôntico realizado com exodontia de 4 pré-molares. Observa-se que a diminuição de $1^{\circ}$ no ângulo formado pela intersecção do longo eixo do incisivo superior com o plano horizontal de Frankfurt produz um aumento de $1,1^{\circ}$ no ângulo $\mathrm{Z}$ de Merrifield, definido pela linha que vai do pogônio mole ao lábio mais protruído, com o plano de Frankfurt, nos pacientes com Classe II, $1^{\text {a }}$ divisão ${ }^{6}$.

Alterações no comprimento e espessura do lábio superior também podem ocorrer, em decorrência da retração dos incisivos superiores em pacientes com má oclusão de Classe II, $1^{\text {a }}$ divisão, submetidos a extrações de pré-molares. Uma retração média de $4,68 \mathrm{~mm}$ dos incisivos superiores produz um aumento médio da espessura do lábio superior de $3,19 \mathrm{~mm}$, e observa-se uma inter-relação entre o aumento da espessura do lábio superior e o alívio de sua tensão. $\mathrm{O}$ comprimento do lábio superior também aumenta significativamente $(0,94 \mathrm{~mm}$, em média, ao final do tratamento), 
mas isto não pode ser considerado como padrão, devido à variação individual apresentada ${ }^{8}$.

Este trabalho objetivou avaliar cefalometricamente as alterações do ângulo nasolabial decorrentes do tratamento ortodôntico, com e sem extração dentária, e determinar a correlação entre as alterações deste ângulo e as seguintes variáveis: inclinação dos incisivos superiores, plano labial e plano da base do nariz.

\section{MATERIAL E MÉTODOS Material}

Do acervo de documentações ortodônticas pertencentes à disciplina de Ortodontia do Centro de Odontologia e Pesquisa da Faculdade de Odontologia da PUC-Minas, analisaram-se telerradiografias, obtidas em norma lateral, de 748 jovens que se submeteram ao tratamento ortodôntico corretivo, na referida disciplina. Elegeram-se trinta jovens, leucodermas, da região de Belo Horizonte, do gênero feminino, que apresentavam inicialmente má oclusão de Classe II, $1^{\text {a }}$ divisão, com padrão vertical de crescimento determinado pelo ângulo SN.GoGn $\geq 32^{\circ}$, segundo os preceitos de Steiner ${ }^{13}$. Quinze delas, com idade média de 11 anos e 10 meses, foram tratadas com extrações dos quatro primeiros pré-molares, caracterizando o grupo experimental; e outras quinze, com idade média de 12 anos e 9 meses, sem extrações, caracterizando o grupo controle. Os pacientes que utilizaram ativadores associados aos aparelhos corretivos foram excluídos, bem como aqueles que apresentavam Classe II, $1^{\text {a }}$ divisão, subdivisão. O tratamento foi realizado pelos alunos de pós-graduação (especialização) em Ortodontia, empregando-se a técnica do arco de canto associado ao aparelho extrabucal de tração alta.

\section{Métodos}

Os autores identificaram as estruturas dentoesqueléticas e do perfil tegumentar e definiram cinco pontos cefalométricos de interesse: 1) S (sela túrcica): ponto situado na região central da sela túrcica do osso esfenóide; 2) N (Násio): situado na porção mais anterior da sutura fronto-nasal; 3) PCm (columela posterior): situado na confluência entre a margem inferior da columela nasal e o lábio superior; 4) Ls (lábio superior): situado no ponto mais anterior do vermelhão do lábio superior; 5) Is (incisivo superior): ponto mais incisal da coroa do incisivo central superior mais proeminen$\mathrm{te}^{3,5,8,14}$. A partir desses pontos, definiram-se quatro planos: S-N, Ls-PCm, PCm-tang (plano tangente à base do nariz, passando por PCm) e plano Is (longo eixo do incisivo, passando por Is). Um quinto plano, definido como a linha horizontal de referência, foi construído reduzindo-se $7^{\circ}$ do plano Sela-Násio ${ }^{5,9,14}$. Finalmente, determinaram-se as quatro medidas angulares utilizadas no trabalho: o ângulo nasolabial, Ls-PCm.PCm-tang; a inclinação da base do nariz, $\mathrm{PCm}$-tang. $\mathrm{SN}\left(7^{\circ}\right)$; a inclinação do lábio superior, $\mathrm{Ls}-\mathrm{PCm} . \mathrm{SN}\left(7^{\circ}\right)$; e a inclinação do incisivo superior, Is.SN $\left(7^{\circ}\right)^{5,9,14}$ (Fig. 1).

\section{Análise estatística}

Inicialmente, efetuou-se uma análise descritiva dos dados, com o objetivo de avaliar a igualdade de distribuição entre os grupos, em relação à idade e ao tempo de tratamento.

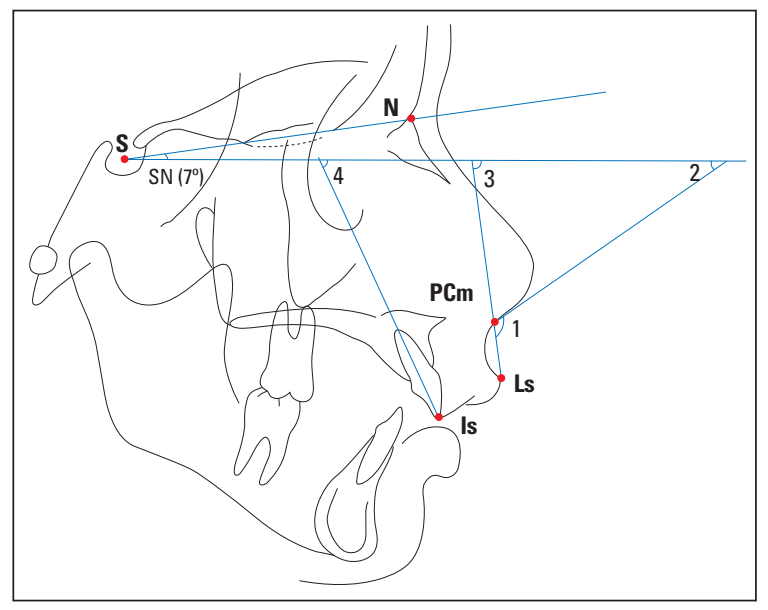

FIGURA 1 - Identificação dos pontos, planos e ângulos usados no trabalho: Pontos: $\mathbf{S}=$ sela túrcica; $\mathbf{N}=$ Násio; $\mathbf{P C m}=$ columela posterior; $\mathbf{L s}$ = lábio superior; Is = incisivo superior. Linhas: linha S-N; linha S-N( $\left(\mathbf{7}^{\circ}\right)$; linha $\mathbf{L s}-\mathbf{P C m}$; linha PCm-tang; linha Is. Ângulos: 1 = ângulo nasolabial; 2 = ângulo PCm-tang. $\operatorname{SN}\left(7^{\circ}\right)$; 3 = ângulo $\operatorname{Ls}-\mathrm{PCm} \cdot \mathrm{SN}\left(7^{\circ}\right) ; 4$ = ângulo Is.SN $\left(7^{\circ}\right)$. 
Para avaliar as correlações entre as medidas, foi utilizado o método de Spearman.

Para comparação das variáveis em relação ao tempo inicial e final, foi utilizado o teste de Wilcoxon para amostras dependentes.

Para verificar se a extração influenciou na variação das medidas ao longo do tempo, realizou-se o teste de Mann-Whitney (teste de Wilcoxon para amostras independentes).

Também foi utilizado o teste de Mann-Whitney para a comparação entre as medidas nos tempos iniciais e finais.

Entre as medidas do grupo com extração dentária, observou-se uma correlação positiva significativa entre os ângulos nasolabial e Ls.PCm.SN $\left(7^{\circ}\right)$; e nasolabial e PCm.SN $\left(7^{\circ}\right)$, ou seja, quando ocorre um aumento no ângulo nasolabial, observa-se um aumento nos ângulos Ls.PCm.SN $\left(7^{\circ}\right)$ e PCm. $\mathrm{SN}\left(7^{\circ}\right)$ (Tab. 1). A mesma correlação ocorreu no grupo sem extração (Tab. 3).

$\mathrm{Na}$ comparação entre as medidas nos grupos com e sem extração, entre os tempos inicial e final, somente a variável Is.SN $\left(7^{\circ}\right)$, no tempo inicial, apresentou diferença (Tab. 5). Isso demonstra que as crianças com necessidade de extração dos pré-molares apresentaram valores iniciais do ângulo Is. $\mathrm{SN}\left(7^{\circ}\right)$ menores do que as crianças sem necessidade de extração, ou seja, as crianças com necessidade de extração apresentaram os incisivos mais projetados.

Tabela 1 - Correlação entre as variáveis no grupo com extração dentária.

\begin{tabular}{|c|c|c|c|c|}
\hline variável & $\begin{array}{c}\text { correlação } \\
\text { p-valor }\end{array}$ & Ls.PCm.SN(7º) & $\operatorname{PCm} \cdot \operatorname{SN}\left(7^{\circ}\right)$ & nasolabial \\
\hline \multirow[b]{2}{*}{$\operatorname{PCm} \cdot \operatorname{SN}\left(7^{\circ}\right)$} & correlação & $-0,1914$ & & \\
\hline & $\mathrm{p}$-valor & 0,4944 & & \\
\hline \multirow[b]{2}{*}{ nasolabial } & correlação & 0,5912 & 0,5966 & \\
\hline & p-valor & 0,0203 & 0,0189 & \\
\hline \multirow[b]{2}{*}{ Is.SN $\left(7^{\circ}\right)$} & correlação & 0,0313 & 0,1799 & 0,1853 \\
\hline & $\mathrm{p}$-valor & 0,9117 & 0,5210 & 0,5086 \\
\hline
\end{tabular}

\section{RESULTADOS}

\section{Jovens submetidas à extração dentária}

Observou-se uma correlação positiva significativa entre os ângulos nasolabial e a posição do lábio superior, medida pelo ângulo Ls.PCm.SN $\left(7^{\circ}\right)$. Uma correlação positiva também foi verificada entre o ângulo nasolabial e a base do nariz, medida pelo ângulo $\mathrm{PCm} . \mathrm{SN}\left(7^{\circ}\right)$ (Tab. 1).

Os ângulos do lábio superior e do incisivo superior apresentaram um aumento estatisticamente significante entre o tempo inicial e final, enquanto o ângulo da base do nariz não sofreu alterações significativas durante o tratamento. Conseqüentemente, no caso dos tratamentos com exodontia, a alteração do ângulo nasolabial ocorreu, principalmente, devido a mudanças na inclinação do lábio superior (Tab. 2).

\section{Jovens não submetidas à extração dentária}

As correlações obtidas neste grupo foram similares àquelas obtidas no grupo das jovens com extração, ou seja, alterações nas inclinações do lábio superior, medidas pelo ângulo Ls.PCm.SN $\left(7^{\circ}\right)$, e na base do nariz, medidas pelo ângulo $\mathrm{PCm}$. $\mathrm{SN}\left(7^{\circ}\right)$, produziram alterações do ângulo nasolabial (Tab. 3).

Nesse grupo, nenhuma medida foi estatisticamente influenciada pelo tempo. Pequenas alterações médias de $1^{\circ}$ a $2^{\circ}$, sem significância estatística, ocorreram durante o período de tratamento (Tab. 4).

Tabela 2 - Comparação entre o tempo inicial e final no grupo com extração dentária.

\begin{tabular}{cccc} 
variável & tempo & mediana & p-valor \\
Ls.PCm.SN $\left(7^{\circ}\right)$ & T0 & 77,5 & 0,048 \\
& T1 & 84,0 & \\
PCm.SN $\left(7^{\circ}\right)$ & T0 & 22,0 & 0,268 \\
& T1 & 24,0 & \\
nasolabial & T0 & 104,0 & 0,071 \\
& T1 & 112,0 & \\
Is.SN $\left(7^{\circ}\right)$ & T0 & 62,0 & 0,001 \\
& T1 & 73,0 & \\
\hline
\end{tabular}


Tabela 3 - Correlação entre as variáveis no grupo sem extração dentária.

\begin{tabular}{|c|c|c|c|c|}
\hline variáveis & $\begin{array}{c}\text { correlação } \\
\text { p-valor }\end{array}$ & Ls.PCm.SN $\left(7^{\circ}\right)$ & $\operatorname{PCm} \cdot \operatorname{SN}\left(7^{\circ}\right)$ & nasolabial \\
\hline \multirow{2}{*}{$\operatorname{PCm} \cdot \operatorname{SN}\left(7^{\circ}\right)$} & correlação & $-0,2372$ & & \\
\hline & p-valor & 0,3947 & & \\
\hline \multirow{2}{*}{ nasolabial } & correlação & 0,6139 & 0,5459 & \\
\hline & p-valor & 0,0149 & 0,0353 & \\
\hline \multirow[t]{2}{*}{ Is.SN $\left(7^{\circ}\right)$} & correlação & 0,1418 & $-0,2090$ & $-0,1626$ \\
\hline & $\mathrm{p}$-valor & 0,6141 & 0,4548 & 0,5625 \\
\hline
\end{tabular}

\section{Comparação entre as jovens com e sem ex- tração}

Os resultados demonstraram que somente a inclinação do incisivo superior, medida pelo ângulo Is.SN $\left(7^{\circ}\right)$, apresentou uma diferença estatisticamente significante entre as jovens com e sem extração, no tempo inicial. Isto sugere que as jovens com necessidade de extração dos prémolares apresentaram os incisivos superiores mais projetados, com o ângulo Is.SN $\left(7^{\circ}\right)$ menor do que as jovens sem necessidade de extração. Ao final do tratamento, os dois grupos, com e sem extração, obtiveram valores do ângulo Is.SN $\left(7^{\circ}\right)$ similares estatisticamente, demonstrando que, com o tratamento, as inclinações dos incisivos tornaram-se similares (Tab. 5).

\section{DISCUSSÃO}

Este trabalho avaliou uma amostra de jovens do gênero feminino, com Classe II, $1^{\text {a }}$ divisão, sendo quinze, com idade média de 11 anos e 10 meses, tratadas com extrações dos quatro primeiros prémolares, caracterizando o grupo experimental; e quinze, com idade média de 12 anos e 9 meses, sem extrações, caracterizando o grupo controle.

Os ângulos usados neste trabalho representam as posições de estruturas anatômicas relevantes deste estudo, descritos a seguir: o ângulo nasolabial representa a relação entre o lábio superior e a base do nariz; o ângulo $\mathrm{PCm} . \mathrm{SN}\left(7^{\circ}\right)$ representa a inclinação da base do nariz; o ângulo
Tabela 4 - Comparação entre o tempo inicial e final no grupo sem extração dentária.

$\begin{array}{cccc}\text { variável } & \text { tempo } & \text { mediana } & \text { p-valor } \\ \text { Ls.PCm.SN }\left(7^{\circ}\right) & \text { T0 } & 82,5 & 0,47 \\ & \text { T1 } & 84,0 & \\ \text { PCm.SN }\left(7^{\circ}\right) & \text { T0 } & 24,5 & 0,328 \\ & \text { T1 } & 23,5 & \\ \text { nasolabial } & \text { T0 } & 111,0 & 1 \\ & \text { T1 } & 112,0 & \\ \text { Is.SN }\left(7^{\circ}\right) & \text { T0 } & 68,0 & 0,394 \\ & \text { T1 } & 67,0 & \end{array}$

Tabela 5 - Comparação dos tempos iniciais e finais entre pacientes com e sem extração dentária.

\begin{tabular}{|c|c|c|c|c|}
\hline variável & tempo & extração & mediana & $\mathrm{p}$-valor \\
\hline \multirow{4}{*}{ Ls.PCm.SN(7º) } & \multirow{2}{*}{ T0 } & não & 82,5 & \multirow{2}{*}{0,1351} \\
\hline & & sim & 77,5 & \\
\hline & \multirow{2}{*}{$\mathrm{T} 1$} & não & 84,0 & \multirow{2}{*}{0,9173} \\
\hline & & $\operatorname{sim}$ & 84,0 & \\
\hline \multirow{4}{*}{$\mathrm{PCm} \cdot \mathrm{SN}\left(7^{\circ}\right)$} & \multirow{2}{*}{ TO } & não & 24,5 & \multirow{2}{*}{0,7085} \\
\hline & & $\operatorname{sim}$ & 22,0 & \\
\hline & \multirow{2}{*}{$\mathrm{T} 1$} & não & 23,5 & \multirow{2}{*}{0,7873} \\
\hline & & sim & 24,0 & \\
\hline \multirow{4}{*}{ nasolabial } & \multirow{2}{*}{ TO } & não & 111,0 & \multirow{2}{*}{0,1459} \\
\hline & & $\operatorname{sim}$ & 104,0 & \\
\hline & \multirow{2}{*}{ T1 } & não & 112,0 & \multirow{2}{*}{0,9172} \\
\hline & & sim & 112,0 & \\
\hline \multirow{4}{*}{ Is.SN $\left(7^{\circ}\right)$} & \multirow{2}{*}{ TO } & não & 68,0 & \multirow{2}{*}{0,0562} \\
\hline & & $\operatorname{sim}$ & 62,0 & \\
\hline & \multirow{2}{*}{ T1 } & não & 67,0 & \multirow{2}{*}{0,0965} \\
\hline & & sim & 73,0 & \\
\hline
\end{tabular}

LsPCm.SN $\left(7^{\circ}\right)$ representa a inclinação do lábio superior; e o ângulo Is. $\mathrm{SN}\left(7^{\circ}\right)$ representa a inclinação do incisivo superior.

Todas as radiografias foram traçadas pelo mesmo pesquisador, bem como a realização das medidas angulares utilizadas neste estudo. As medidas encontradas foram tabuladas e enviadas para análise estatística.

No grupo com extrações dos pré-molares, 
ocorreu uma correlação positiva significativa entre o ângulo nasolabial e a inclinação do lábio superior e inclinação da base do nariz, ou seja, tanto o lábio superior quanto a base do nariz podem produzir alterações no ângulo nasolabial. No entanto, observou-se que o tratamento ortodôntico não influenciou a inclinação da base do nariz. Alterações na inclinação deste plano devem-se, principalmente, ao crescimento, fato que não foi constatado neste estudo, durante o tempo observado ${ }^{7}$. Portanto, o aumento do ângulo nasolabial ocorreu devido à retração do lábio superior, em decorrência da retração dos incisivos superiores, nas jovens que se submeteram ao tratamento com extração dos pré-molares.

A proporção entre a quantidade de retração dos incisivos e a retração do lábio superior é, em média, de 1:0,75mm em pacientes com selamento labial e de 1:0,70mm nos sem selamento labial. Mas existe uma grande variabilidade individual e o ângulo nasolabial obtuso não é um resultado direto da retração dos incisivos superiores ${ }^{10}$. Diferentemente, observa-se que o retroposicionamento dos incisivos superiores, devido à extração, contribui para a correção da má oclusão de Classe II, $1^{\text {a }}$ divisão, e influencia no aumento do ângulo nasolabial $^{7,4}$, sendo que, para cada milímetro de retração dos dentes ântero-superiores, o ângulo nasolabial aumenta $1,49^{\circ}$. O presente trabalho constatou a correlação, mas não mediu essa proporção.

É importante ressaltar que a extração dos prémolares pode não ser o único fator responsável na variação das medidas analisadas. A idade e a duração do tratamento também podem interferir. Portanto, para diminuir o efeito desses dois fatores (idade e tempo de tratamento), foi necessário controlá-los com uma distribuição semelhante nos grupos estudados. As análises estatísticas utilizadas demonstraram uma similaridade entre os dois grupos, nestes dois aspectos.

Tanto no grupo com exodontia quanto no grupo sem exodontia dos pré-molares, observou-se alterações médias de $1^{\circ}$ no ângulo do plano da base do nariz, sem significância estatística, sugerindo que, no período avaliado, o crescimento não foi suficiente para alterar este ângulo ${ }^{7}$.

Analisando o grupo de pacientes que não sofreram extração dos pré-molares, observou-se que a inclinação do lábio superior aumentou, em média, $1^{\circ}$ após o tratamento ortodôntico e a inclinação do incisivo superior também aumentou $1^{\circ}$, mas o ângulo nasolabial não variou de forma estatisticamente significante. As variáveis estudadas apresentaram correlações positivas similares àquelas encontradas no grupo com extração de pré-molares. Ainda neste grupo sem extração, nenhuma medida foi influenciada pelo tempo, ao contrário do grupo com extração, no qual somente a inclinação da base do nariz não sofreu esta influência. Contrariando estes resultados, observou-se, em outros trabalhos, que o movimento da borda do incisivo superior não apresentou uma correlação com o ângulo nasolabial ${ }^{15}$, e as alterações no ângulo nasolabial não promoveram alterações significantes no perfil facial ${ }^{12}$.

No início do tratamento, as jovens do grupo com extração apresentaram incisivos superiores mais protruídos e mais inclinados do que as que não necessitaram de extração, mas a terapia ortodôntica deixou esses valores semelhantes entre os dois grupos, ao final do tratamento. Os demais ângulos (inclinação do lábio superior, inclinação da base do nariz e ângulo nasolabial) não apresentaram diferenças significativas entre os grupos, no início do tratamento. O tratamento alterou alguns valores, mas não promoveu uma diferença entre eles ao final do tratamento, ou seja, todas as medidas analisadas tenderam a se igualar com o tratamento ortodôntico.

Os perfis das jovens sem extração dentária foram avaliados como "satisfatórios" ao início do tratamento, e não ocorreram modificações estatisticamente significantes neste grupo, durante o tratamento. Os perfis das jovens tratadas com extração dos pré-molares se alteraram com o tratamento e se aproximaram dos valores obtidos nas 
jovens sem extração. Estes resultados sugerem que uma terapia ortodôntica bem planejada, dentro de protocolos já estabelecidos, vai direcionar os resultados para perfis favoráveis, com ou sem extrações dentárias. Generalizações sobre os efeitos negativos da extração dos primeiros pré-molares no perfil são falsas, visto que, claramente, na grande maioria dos pacientes, a alteração do perfil é controlada durante um tratamento ortodôntico bem planejado e executado ${ }^{2}$.

\section{CONCLUSÕES}

A partir dos resultados deste trabalho, pode-se concluir que:

1. O ângulo nasolabial aumentou com o tratamento ortodôntico, nas jovens que se submeteram a extrações dentárias de pré-molares, principalmente devido às alterações do lábio superior.

2. Existiu uma correlação positiva entre as alterações da inclinação do incisivo superior, do lábio superior e do ângulo nasolabial.

3. O crescimento nasal, durante o período do estudo, não influenciou as alterações do ângulo nasolabial.

4. Os ângulos nasolabial, do lábio superior, do incisivo superior e da base do nariz não se alteraram significativamente, durante o tratamento ortodôntico, nas jovens que não se submeteram a extrações dentárias de pré-molares.

5. As extrações de pré-molares alteraram as inclinações do lábio superior, do incisivo superior e do ângulo nasolabial, tornando essas medidas similares, ao final do tratamento, àquelas do grupo sem extrações, ou seja, esses valores tendem a se igualar com o tratamento ortodôntico.

\title{
Assessment of the nasolabial angle after orthodontic treatment with and without extraction of the first premolars
}

\begin{abstract}
Aim: To cephalometrically evaluate the changes in the nasolabial angle of the patients submitted to orthodontic treatment with and without extractions and correlate them with upper incisor inclination, upper lip position and the base of the nose. Methods: The sample was composed of pre and posttreatment lateral cephalometric records of 30 female patients with Class II division 1 malocclusion. Fifteen were treated with first premolars extractions and the other fifteen without extractions. The following parameters were measured: nasolabial angle; upper incisor inclination (Is.SN7 ${ }^{\circ}$ angle), upper lip position (Ls-PCm.SN7 ${ }^{\circ}$ angle) and base of the nose (PCm.SN7 ${ }^{\circ}$ angle). Results: The upper incisor inclination and the upper lip position showed a statistically significant increase from T0 to T1 in the extraction group. No statistically significant differences were found for the other parameters in both groups. The correlations between upper lip position, base of the nose and the nasolabial angle were positive. Conclusion: 1) There was a significant increase in the nasolabial angle in the extraction group and it was mainly due to changes in the upper lip position; 2) nasal growth during the study period did not contributed to the nasolabial angle increase; 3) all measurements were not statistically different between the 2 groups at T0 and T1, and 4) a positive correlation was found between the nasolabial angle, lip position and base of the nose in both groups.
\end{abstract}

Key words: Class II division 1. Nasolabial angle. Premolar extraction. Facial profile. 


\section{REFERÊNCIAS}

1. BRANDÃO, A. M. B.; VIGORITO, J. W.; FILHO, L. C. Avaliação das características do perfil tegumentar em pacientes com má oclusão $\mathrm{Cl}$. II div. 1 por meio da análise facial numérica. Ortodontia, São Paulo, v. 34, n. 2, p. 59-65, maio/ ago. 2001.

2. DROBOCKY, O. B.; SMITH, R. J. Changes in facial profile during orthodontic treatment with extraction of four first premolars. Am. J. Orthod. Dentofacial Orthop., St. Louis, v. 95 , no. 3, p. 220-230, Mar. 1989.

3. FITZGERALD, J. P.; NANDA, R. S.; CURRIER, G. F. An evaluation of the nasolabial angle and the relative inclinations of the nose and upper lip. Am. J. Orthod. Dentofacial Orthop., St. Louis, v. 102, no. 4, p. 328-334, Oct. 1992.

4. FREITAS, M. R. et al. Estudo longitudinal das alterações do ângulo nasolabial, em jovens com Classe II, $1^{\text {a }}$ divisão, que se submeteram ao tratamento ortodôntico corretivo. Ortodontia São Paulo, v. 32, n. 1, p. 8-16, jan./ abr. 1999.

5. KAPUST, A. J.; SINCLAIR, P. M.; TURLEY, P. K. Cefalometric effects of face mask/expansion therapy in Class III children: a comparison of three age groups. Am. J. Orthod. Dentofacial Orthop., St. Louis, v. 113, no. 2, p. 204-212, Feb. 1998.

6. LIMA, C. E. O. et al. Perfil facial: alterações cefalométricas em casos tratados com extrações de pré-molares e mecânica de forças direcionais. Rev. Dental Press Ortodon. Ortop. Facial Maringá, v. 6, n. 3, p. 37-46, maio/jun. 2001

7. LO, F. D.; HUNTER, W. S. Changes in nasolabial angle related to maxillary incisor retraction. Am. J. Orthod., St. Louis, v. 82, no. 5, p. 384-391, Nov. 1982

8. MONTERO, S. R.; TAKAHASHI, T.; REICHENBACH, R. C. Alterações do lábio superior decorrentes do tratamento ortodôntico associado a extrações de pré-molares, nos casos de Classe II, divisão 1 de Angle. J. Bras. Ortodon. Ortop.

Facial, Curitiba, v. 8, n. 44, p. 142-154, mar./abr. 2003.
9. RAINS, M. D.; NANDA, R. Soft- tissue changes associated with maxillary incisor retractions. J. Orthod., St. Louis, v. 81, no. 6, p. 481-488, June 1982.

10. RAMOS, A. L. et al. Upper lip changes correlated to maxillary incisor retraction: a metallic implant study. Angle Orthod. Appleton, v. 75, no. 4, p. 499-505, July 2004.

11. SAKIMA, M. T. et al. Estudo do ângulo nasolabial em indivíduos Classe II $1^{a}$ divisão com diferentes padrões faciais. Rev. Dental Press Ortodon. Ortop. Facial, Maringá, v. 6, no. 5, p. 11-15, set./out. 2001.

12. SILVEIRA, C. A. et al. Efeitos dento-esqueléticos-faciais da utilização do aparelho distalizador Jones Jig em tratamento de más oclusões Classe II de Angle. J. Bras. Ortodon. Ortop. Facial, Curitiba, ano 6, n. 31, p. 72-79, jan/ fev. 2001.

13. STEINER, C. C. Cephalometric for you and me. Am. J. Orthod., St. Louis, v. 39, no. 10, p. 729-755, Oct. 1953.

14. TALASS, M. F.; TALASS, L.; BAKER, R. C. Soft-tissue profile changes resulting from retraction of maxillary incisors. Am. J. Orthod. Dentofacial Orthop., St. Louis, v. 91, no. 5, p. 385-394, May 1987.

15. WALDMAN, B. H. Change in lip contour with maxillary incisor retraction. Angle Orthod., Appleton, v. 52, no. 2, p. 129-134, Apr. 1982.
Endereço para correspondência

Flávio Marcos de Almeida

Av. do Contorno, 6777 Sala 1103

CEP: 30.110-935 - Belo Horizonte/MG

E-mail: flaviofafeu2@gmail.com 